Research Paper

\title{
Low Molecular Weight Hydroxyethyl Chitosan- Prednisolone Conjugate for Renal Targeting Therapy: Synthesis, Characterization and In Vivo Studies
}

\author{
Xia-kai He ${ }^{1^{*}}$, Zhi-xiang Yuan ${ }^{2 * \bowtie}$, Xiao-juan $\mathrm{Wu}^{3}$, Chao-qun $\mathrm{Xu}^{2}$, Wan-yu $\mathrm{Li}^{4}$ \\ 1. School of Pharmacy, Chengdu University of Traditional Chinese Medicine, Chengdu, Sichuan, 610075 P. R. China; \\ 2. Institute of pharmacy, Sichuan Academy of Chinese Medicine Sciences, Chengdu, Sichuan, 610041 P. R. China; \\ 3. Integrative Traditional and Western Medicine hospital of Sichuan Province, Chengdu, Sichuan, 610041 P. R. China; \\ 4. School of Pharmacy, Chongqing Medical University, Chongqing, 400016 P. R. China. \\ *Both contributed equally to this work.
}

Corresponding author: Zhi-xiang Yuan; TEL.: +86-28-85213973; Fax: +86-28-85256772; E-mail: zhixiang_yuan@yahoo.cn. 11070318@qq.com.

( ) Ivyspring International Publisher. This is an open-access article distributed under the terms of the Creative Commons License (http://creativecommons.org/ licenses/by-nc-nd/3.0/). Reproduction is permitted for personal, noncommercial use, provided that the article is in whole, unmodified, and properly cited.

Received: 2011.10.26; Accepted: 2011.12.14; Published: 2012.11.06

\begin{abstract}
To further evaluate the potential renal targeting profile of low molecular weight hydroxyethyl chitosan (LMWHC) we developed before, prednisolone (Pre) was conjugated with LMWHC by EDC/NHS chemistry to improve the therapeutic effect of glucocorticoids in vivo. The conjugate was denoted as LMWHC-Pre. The prednisolone content of the conjugate was determined by reversed-phase high-performance liquid chromatography (HPLC) with Kromasil CI 8 column. The results showed that the average coupling degree of prednisolone to LMWHC was $76.7 \pm 3.2 \mu \mathrm{g} \mathrm{mg}^{-1}$. The stability and physicochemical characterization of LMWHC-Pre under various conditions were also investigated. To study the fate of LMWHC-Pre after intravenous (i.v.) administration, fluorescein isothiocyanate (FITC) was coupled to the conjugate to explore the renal targeting efficacy. The in vivo results showed that significant amount of the conjugate was accumulated into the kidneys while negligible signal could be detected when the mixture of FITC-LMWHC and prednisolone was co-administered. The preliminary pharmacodynamics study of LMWHC-Pre showed that the conjugate could effectively alleviate the nephrotic syndrome of rats induced by minimal change nephrosis (MCN) model. Toxicity study also revealed that there was little glucocorticoid-induced osteoporosis by LMWHC-Pre upon 20 days of treatment. From this study, LMWHC-Pre may be employed as an effective potential drug candidate for the treatment of chronic renal disease.
\end{abstract}

Key words: renal targeting; prednisolone; LMWHC-Pre conjugate; MCN model; osteoporosis.

\section{Introduction}

Chronic renal disease is characterized by massive urinary protein excretion and a progressive decline of renal function. The renal proximal tubular cell, triggered by long-term exposure to proteins, is believed to play a pivotal role in the cascade of pathophysiological processes towards end-stage renal failure (ESKD) [1], which is irreversible and perma- nent. As the pathogenic condition becomes worse, renal replacement therapy (RRT), such as dialysis or renal transplantation, has to be applied to sustain the lives of patients. However, these therapies are generally expensive and will cause various severe side effects.

Prednisolone, a synthetic glucocorticoid, has 
been used extensively in the treatment of patients with renal disease. Treatment with prednisolone results in a reduction of proteinuria, suppression of inflammation and a long term renoprotective effect. However, a myriad of complications of glucocorticoid excess have been reported and osteoporosis is considered to be the most serious side effect induced by glucocorticoid [2, 3]. To reduce the glucocorticoid associated renal toxicity, pursuit of specific carriers targeting to kidneys is essential and critical for the clinic.

In our previous studies, low molecular weight hydroxyethyl chitosan (LMWHC) has been developed as a novel renal targeting carrier for renal specific delivery of prednisolone [4]. Specifically, when prednisolone was conjugated to LMWHC with molecular weight of $31 \mathrm{kDa}$ or $19 \mathrm{kDa}$, it presented a relatively higher renal accumulation rate than other candidates, such as prodrugs [5], low-molecular-weight proteins [6-8], sugar-modified low-molecular-weight peptides $[9,10]$ and poly (vinylpyrrolidone-co-dimethyl maleic acid) (PVD) [11-13], etc. [4]. Moreover, LMWHC has the capacity of accumulating specifically in the proximal tubular cells by means of receptor-mediated endocytosis, subsequent to free filtration in the glomerulus [14]. In addition, decreasing the degree of $\mathrm{N}$-acetylation of chitosan can enhance accumulation of LMWHC in the kidneys [15]. The primary amino groups from glucosamine residue remaining on LMWHC can be used for drug conjugation. However, there was little work on the study of conjugating prednisolone to LMWHC and the pharmacodynamics properties of the conjugate.

In this study, a conjugate of LMWHC and prednisolone was designed, synthesized and characterized for the purpose of exploring renal targeting potential, enhancing the therapeutic effect and alleviating the side effect from glucocorticoid. Renal targeting and drug release characteristics of LMWHC-Pre was measured in vivo by imaging with the LT-99D2 Illumatool Dual Light System after FITC was labeled to the conjugate. The pharmacodynamic properties of the conjugate on a rat model of minimal change nephrosis $(\mathrm{MCN})$ were also evaluated. These research data demonstrated the excellent target efficiency and safety of LMWHC-Pre, suggesting its potential for clinical use as a renal drug delivery system.

\section{Materials and methods}

\section{Materials and animals}

LMWHC $(\mathrm{N}$-acetylation degree $=53 \%$, hydroxyethyl groups $=0.841 /$ unit, $\mathrm{Mw}=3.1 \times 10^{4}$ ) was prepared according to our previous studies [15]. Predni- solone hemisuccinate (Pre-suc) (USP27) was supplied by Henan Lihua Co. Ltd (China). Fluorescein isothiocyanate (FITC), 1-ethyl-3-(3-dimethylami-nopropyl) carbodiimide (EDC) and N-hydroxysuccinimide (NHS) were purchased from Sigma-Aldrich Chemical Co. All other chemicals used were of reagent grade.

Adult male (8-week old) of Sprague-Dawley rats (180 200 g) were provided by the Experimental Animal Center of Chengdu University of Traditional Chinese Medicine (China).

\section{Synthesis of Low molecular weight hydroxy- ethyl chitosan-prednisolone (LMWHC-pre)}

LMWHC-Pre conjugate was prepared as previously described with some modification [4]. In brief, prednisolone hemisuccinate (Pre-suc) (115 mg, 0.25 mmol), N-hydroxysuccinmide (NHS) (57.5 mg, 0.50 $\mathrm{mmol}$ ) in $20 \mathrm{ml}$ of ethanol was added in dropwise fashion to LMWHC (100 mg, $3.2 \mathrm{nmol})$ in $30 \mathrm{ml}$ of deionized water, and then 1-ethyl-3-(3-dimethylaminopropyl) carbodiimide (EDC) $(240 \mathrm{mg}, 1.34 \mathrm{mmol})$ was added. Subsequently, the solution was stirred at room temperature for $7 \mathrm{~h}$ with a magnetic stirrer. Then, $200 \mathrm{ml}$ of acetone was added immediately to precipitate the conjugate. The obtained conjugate was repeatedly washed with excessive ethanol to remove uncoupled Pre-suc and other small molecules. Finally, the conjugate was obtained with a yield of $89 \%$ followed by dissolving in $10 \%$ sucrose water and freeze drying. In the period of lyophilization, various concentrations of protective agents such as glucose, mannitol, sucrose and maltose were respectively added to $8.5 \mathrm{mg} \mathrm{ml}^{-1}$ of LMWHC-Pre to screen the optimal protective agents. After vortexing and freeze drying, the candidates were marked by parameters such as sharp, color and dispersion for the optimization. The values of critical relative humidity (CHR) on freeze-dried LMWHC-Pre powder for injection were also investigated to obtain their properties of hygroscopicity. In addition, the stability experiment of conjugate in various $\mathrm{pH}$ buffer solutions and the drug release characteristics were performed. Briefly, $1.8 \mathrm{ml}$ of various $\mathrm{pH}$ buffer solution preheated at $37 \pm 0.5^{\circ} \mathrm{C}$ were each added into $2 \mathrm{mg} \mathrm{ml}^{-1}$ of LMWHC-Pre. Then the solutions were incubated at $37 \pm 0.5^{\circ} \mathrm{C}$ in a shaking bath and $0.5 \mathrm{ml}$ of the solution was withdrawn at $0.5,1,2,4$ and $6 \mathrm{~h}$, respectively. Finally, $10 \mu \mathrm{l}$ samples were injected into HPLC to determine the release rate of LMWHC-Pre in various $\mathrm{pH}$ buffer solutions.

\section{HPLC analysis}

HPLC analysis was performed on a Shimadzu system (Chiyoda-Ku, Kyoto, Japan) consisting of a 20 $\mathrm{ml}$ injector loop, an SPD-10A variable UV-VIS detec- 
tor and a set of Model LC-10AT liquid chromatography including two pumps, a manometric module and a dynamic mixer. Separations were carried out using a Kromasil C18 reverse phase column $(150 \times 4.6$ $\mathrm{mm}$ ID, $5 \mu \mathrm{m})$. The mobile phase consisted of $38 \%$ acetonitrile and $62 \%$ buffer $(0.05 \mathrm{M}$ trisodium citrate adjusted to $\mathrm{pH} 4.1$ with phosphoric acid), which was filtered through $0.45 \mu \mathrm{m}$ microporous membrane before use. The flow rate was $1 \mathrm{ml} \mathrm{min}^{-1}$ at $35^{\circ} \mathrm{C}$, and the column effluent was detected at $254 \mathrm{~nm}$.

HPLC was used to characterize and quantify the average coupling degree of prednisolone to LMWHC [16]. In brief, $0.5 \mathrm{ml}$ aliquot of the conjugate $\left(2 \mathrm{mg} \mathrm{ml}^{-1}\right)$ was mixed with $25 \mu \mathrm{l}$ of $1 \mathrm{M} \mathrm{NaOH}$ for hydrolysis at $25{ }^{\circ} \mathrm{C}$. After $10 \mathrm{~min}, 25 \mu \mathrm{l}$ of $1 \mathrm{M} \mathrm{HCl}$ was added to neutralize the excess amount of $\mathrm{NaOH}$ followed by adding $0.45 \mathrm{ml}$ of mobile phase solution. After vortexing, $10 \mu l$ of the supernatant was then injected into the HPLC system to measure the amount of prednisolone. Unbound Pre-suc was determined by the same procedure without the process of hydrolysis: 0.5 $\mathrm{ml}$ of the conjugate aqueous solution $\left(2 \mathrm{mg} \mathrm{ml}^{-1}\right)$ was mixed with $0.45 \mathrm{ml}$ of mobile phase solution. After vortex, $10 \mu \mathrm{l}$ of the supernatant was injected into the HPLC system. The total amount of prednisolone (W Pre-tot) and the amount of Pre-suc (W Pre-suc) were obtained through the peak area of the conjugate aqueous solution after hydrolysis and unbound Pre-suc aqueous solution without hydrolysis. The average coupling degree (D) of prednisolone to LMWHC was estimated with the following equation 1 :

$$
\mathrm{D}=\frac{\mathrm{W}_{\text {Pre-tot }}-\left(\mathrm{W}_{\text {Pre-suc }} \times \frac{\mathrm{M}_{\text {Pre }}}{\mathrm{M}_{\text {Pre-suc }}}\right)}{\mathrm{W}_{\text {conjugate }}}
$$

$\mathrm{W}_{\text {conjugate: the amount of the conjugate. }}$

$\mathrm{M}_{\text {Pre: }}$ the relative molecular weight of prednisolone.

$M$ Pre-suc: the relative molecular weight of Pre-suc.

\section{Preparation of FITC-labeled LMWHC-Pre}

LMWHC-Pre $(300 \mathrm{mg})$ was dissolved in $\mathrm{Na}-$ $\mathrm{HCO}_{3} / \mathrm{Na}_{2} \mathrm{CO}_{3}$ buffer solution $(30 \mathrm{ml}, 0.5 \mathrm{M}, \mathrm{pH} 9.0)$ and $20 \mathrm{ml}$ of fluorescein isothiocyanate (FITC) solution $\left(1 \mathrm{mg} \mathrm{ml}^{-1}\right)$ was added dropwise to the buffer solution. Then the solution was stirred at room temperature for $12 \mathrm{~h}$ with a magnetic stirrer. Subsequently, $150 \mathrm{ml}$ of acetone was added to precipitate the product. The obtained conjugate was rinsed with excessive ethanol to remove uncoupled FITC and other small molecules. Finally, the conjugate was dissolved into appropriate volume of distilled water and underwent the process of freeze-drying.

To determine the stability of FITC-labeled conjugate (FITC-LMWHC-Pre), firstly, FITC standard solutions $\left(0.5,1.0,2.0,4.0,6.0,12.0,16.0 \mathrm{mg} \mathrm{ml}^{-1}\right)$ in $0.05 \mathrm{~mol}^{-\mathrm{L}^{-1}}$ of PBS solution $(\mathrm{pH}=8.0)$ were prepared and the fluorescence intensities of were determined by a fluorescence spectrophotometer $\left(\lambda_{\mathrm{ex}}=492 \mathrm{~nm}\right.$, $\left.\lambda_{\mathrm{em}}=519 \mathrm{~nm}\right)$. A linear relationship between the concentrations of FITC standard solution and fluorescence intensities was obtained. Afterwards, FITC-LMWHC-Pre was dissolved into PBS solution $(0.05 \mathrm{M}, \mathrm{pH} 7.4)\left(\sim 10 \mathrm{mg} \mathrm{ml}^{-1}\right)$. After incubation at 37 ${ }^{\circ} \mathrm{C}$ in a shaking bath, $0.5 \mathrm{ml}$ of aliquots was withdrawn at time of $1,2,4,6,12$ and $24 \mathrm{~h}$, respectively followed by adding $1.5 \mathrm{ml}$ of acetone to precipitate the solutions. Then, the precipitate was repeatedly washed with ethanol and dried under vacuum at 30 ${ }^{\circ} \mathrm{C}$ for accurate weighing. PBS $(0.05 \mathrm{M}, \mathrm{pH} 8.0)$ was added to dissolve the precipitate and the fluorescence intensity of the solutions could be calculated respectively according to the standard curve. Moreover, FITC labeling efficiency could be evaluated by the fluorescence intensity and the weight of precipitate. Finally, the cumulative release profile of FITC was determined with the fluorescent labeling efficiency and the labeling degree of FITC to the conjugate.

\section{In vivo behavior of FITC-LMWHC-Pre}

In vivo experiments were performed using 6 male Kunming mice (6-week old, $27.5 \pm 2.5$ g) provided by the Laboratory Animal Center of the Chengdu University of Traditional Chinese Medicine; all procedures of the animal studies were approved by the animal ethical experimentation committee, according to the requirements of the National Act on the use of experimental animals (People's Republic of China). The mice were housed on standard laboratory chow and water ad libitum until the time of the experiment. Animals were randomly placed in one of the two groups: the conjugate group $(n=3)$, the mice were each injected through caudal vein with FITC-LMWHC-Pre (100 mg kg-1); the control group (n $=3$ ), the mice were injected through caudal vein with the equivalent mixture of FITC and LMWHC-Pre (equal to the dosage of the conjugate group). The mice were sacrificed under isoflurane anesthesia at $60 \mathrm{~min}$ post-injection.

All the tissues were imaged at the exciting wavelength of 470nm applying the LT-99D2 Illumatool Dual Light System (Lightools Research, USA) after shaving the mice to expose the tissues $\left(\lambda_{\mathrm{ex}}=492\right.$ $\mathrm{nm}, \lambda_{\mathrm{em}}=519 \mathrm{~nm}$ ). The images were recorded by a built-in CCD camera. Meanwhile, the tissues were harvested and imaged by the same Dual Light System. 


\section{Preliminary pharmacodynamics studies of LMWHC-Pre}

According to the previous work [17], MCN was employed as a pathological model, which was induced by a single injection of daunorubicin hydrochloride $\left(12 \mathrm{mg} \mathrm{kg}^{-1}\right)$ through caudal vein of rats.

Experiments were performed on a total of 20 8 -week old male Sprague-Dawley rats $(180 \pm 20 \mathrm{~g})$. The rats were housed on standard laboratory chow and water ad libitum until the time of the experiment. Animals were randomly placed in one of the four groups: normal, the rats were housed without injection $(n=5)$; blank, the rats were treated with a single dose of daunorubicin hydrochloride $\left(12 \mathrm{mg} \mathrm{kg}^{-1}\right)$ but without any other injections $(n=5)$; control, the rats were treated with a single dose of daunorubicin hydrochloride $\left(12 \mathrm{mg} \mathrm{kg}^{-1}\right)$ and followed with injection of Prednisolone $\left(3.0 \mathrm{mg} \mathrm{kg}^{-1} \cdot \mathrm{d}^{-1}\right)$ for 14 days $(\mathrm{n}=5)$; and treatment, the rats were treated with a single dose of daunorubicin hydrochloride $\left(12 \mathrm{mg} \mathrm{kg}^{-1}\right)$ and followed with injection of LMWHC-Pre (39.1 $\mathrm{mg} \cdot \mathrm{kg}^{-1} \cdot \mathrm{d}^{-1}$, equal to the dose of prednisolone of the control group) for 14 days $(n=5)$. All the rats were weighed every three days. The dosages were adjusted according to the body weight. Each rat was housed in a metabolism cage and the urine voided during $24 \mathrm{~h}$ was collected in tubes at the day before injection of daunorubicin hydrochloride and at the 7th day and the 14th day post-injection. The volume of the urine was recorded and vortexed, then small amounts of the urine were sampled and centrifuged for $10 \mathrm{~min}(4000$ rpm), the supernatant was used to analyze the content of urinary protein by using a urinary protein kit (Nanjing Jiancheng Bioengineering Institute). After treatment, $2 \mathrm{ml}$ of blood samples were collected from the ocular artery and placed in heparinized EP tubes followed by centrifugation at $6000 \mathrm{rpm}$ for $10 \mathrm{~min}$ to collect $0.5 \mathrm{ml}$ plasma. The biochemical indexes such as albumin (ALB), blood urine nitrogen (BUN), creatinine (CREA) and total cholesterol (Tc) of plasma were monitored by MODULAR P-800 full-automatic biochemical analysis apparatus (Roche, USA).

\section{The effect of LMWHC-Pre on bone mineral density of normal rats}

Experiments were carried out on 9 6-week old male Sprague-Dawley rats $(120 \pm 15 \mathrm{~g})$. Animals were randomly placed in one of the three groups: normal group, the rats were without injection and housed for 20 days $(n=3)$; control group, the rats were treated with prednisolone $\left(3.0 \mathrm{mg} \mathrm{kg}-1 \cdot \mathrm{d}^{-1}\right)$ for 20 days $(\mathrm{n}=3)$; and conjugate group, the rats were treated with LMWHC-Pre $\left(39.1 \mathrm{mg} \mathrm{kg}^{-1} \cdot \mathrm{d}^{-1}\right.$, equal to the dose of prednisolone of the control group) for 20 days $(n=3)$.
All the rats were weighed every three days. The dosages were also changed along with the body weight. On the 21th day, the rats were anesthetized by intraperitoneal injection of chloral hydrate (300 $\mathrm{mg} \cdot \mathrm{kg}^{-1}$ ) and were placed flatwise on the apparatus to determine the bone mineral density of each rat by iDXA (Lunar, USA).

\section{Results}

\section{Preparation of LMWHC-Pre conjugate and FITC-labeled LMWHC-Pre}

The synthesis route of LMWHC-Pre was described in Figure 1. To evaluate the average coupling degree of prednisolone in the conjugate, HPLC was used to determine the amount of Pre-suc before hydrolysis and the amount of Pre after hydrolysis. The results were shown in Figure 2. The peak of Pre-suc appeared at $t_{R}=8.8 \mathrm{~min}$ (Figure $2 \mathrm{~A}$ ) while the peak of Pre after being hydrolyzed by $\mathrm{NaOH}$ appeared at $\mathrm{t}_{\mathrm{R}}=$ 6.8 min (Figure 2B). The amounts of Pre-suc and Pre were calculated by integrating the peak areas of Pre-suc and Pre, respectively. The calculation showed that the prednisolone content in the LMWHC-Pre conjugate was $76.7 \pm 3.2 \mu \mathrm{g} \mathrm{mg}^{-1}$. On the screening of the freeze-dried sterile powder for injection of LMWC-Pre, $10 \%$ sucrose was found to be optimal as freeze-drying protective agent. In addition, the CRH value of freeze-dried powder was also measured to be approximately $76 \%$, which means that its lyophilized formulation should be stored in desiccators under dry circumstance. The stability results of LMWHC-Pre in various $\mathrm{pH}$ buffer solutions were summarized in Table 1 . These data showed that the conjugate appeared to be highly stable in acidic solutions while it was hydrolyzed to the parent drug in both neutral and alkaline solutions.

To observe distinctly the localization of LMWHC-Pre in vivo, FITC-labeled LMWHC-Pre was synthesized as molar ratio of LMWHC-Pre and FITC was 15:1 in the present studies. As shown in Figure 3, FITC-LMWHC-Pre was stable in PBS ( $\mathrm{pH}=7.4)$, for its cumulative release was lower than $3 \%$ at time of $24 \mathrm{~h}$.

\section{In vivo behavior of FITC-LMWHC-Pre}

To explore the specific localization of LMWHC-Pre in vivo, fluorescence imaging was applied to visualize the accumulation of FITC-labeled LMWHC-Pre in the kidneys in mice. As shown in Figure $4 \mathrm{C}$ and $4 \mathrm{E}$, the kidneys were the only tissues with detectable fluorescence within $60 \mathrm{~min}$. Besides, administration of the mixture of free FITC and LMWHC-Pre resulted in a non-specific body-wide 
distribution of fluorescence (Figure 4B and 4D). LMWHC-Pre might have the capacity of accumulaTherefore, the visual images revealed that tion in the kidney specifically.

Table I. Release rate of prednisolone from LMWHC-Pre in various $\mathrm{pH}$ phosphate buffers.

\begin{tabular}{llllll}
\hline Time $(\mathrm{h})$ & $\mathrm{pH} 3.0$ & $\mathrm{pH} 5.0$ & $\mathrm{pH} 7.0$ & $\mathrm{pH} 7.4$ & $\mathrm{pH} 8.0$ \\
\hline 0 & $0.00 \%$ & $0.00 \%$ & $0.00 \%$ & $0.00 \%$ & $0.00 \%$ \\
0.5 & $0.76 \%$ & $0.85 \%$ & $5.82 \%$ & $7.51 \%$ & $15.98 \%$ \\
1 & $0.92 \%$ & $0.81 \%$ & $14.63 \%$ & $2.68 \%$ & $27.73 \%$ \\
2 & $1.38 \%$ & $1.25 \%$ & $25.89 \%$ & $39.40 \%$ & $49.64 \%$ \\
4 & $1.45 \%$ & $2.47 \%$ & $34.52 \%$ & $54.29 \%$ & $69.04 \%$ \\
6 & $1.62 \%$ & $4.11 \%$ & & $77.50 \%$ \\
\hline
\end{tabular}

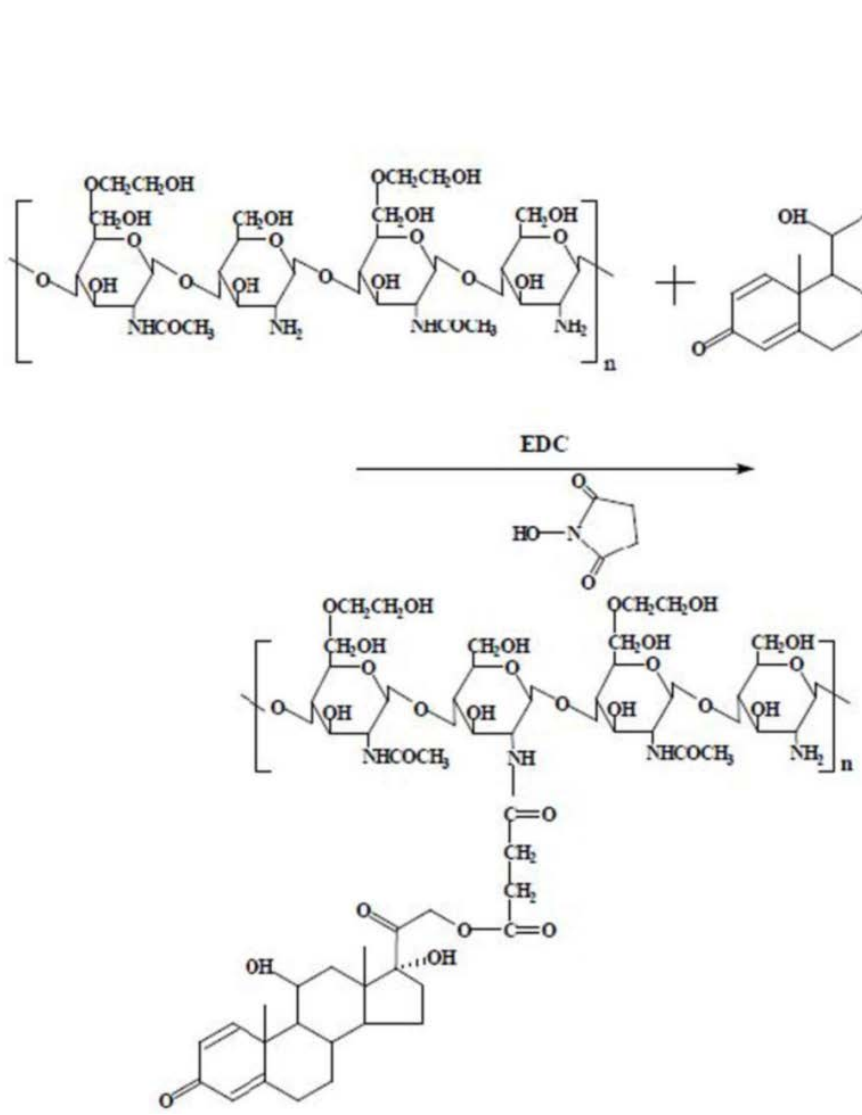

Figure I. Synthetic route of LMWHC-Pre.

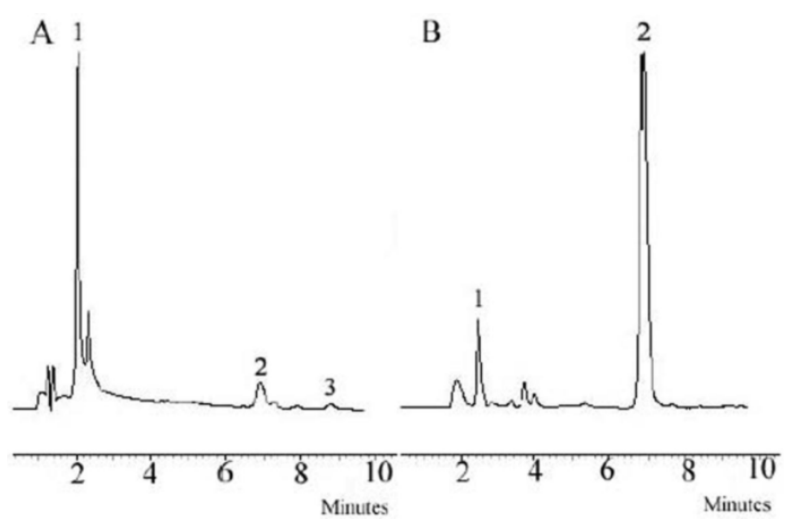

Figure 2. Chromatograms of (A) LMWHC-Pre conjugate, (B) conjugate hydrolyzed with $\mathrm{NaOH}$. Chromatographic peaks: I, LMWHC-Pre; 2, Pre; 3, Pre-Suc. 

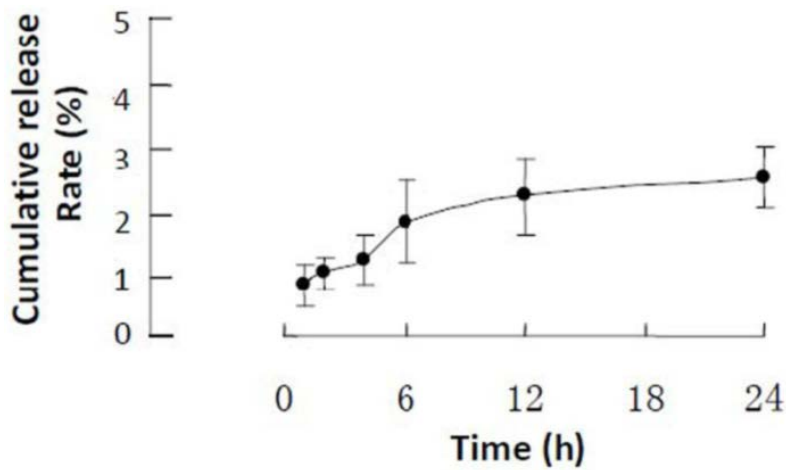

Figure 3. Cumulative release rate of FITC from FITC-LMWHC-Pre conjugate incubated at $37^{\circ} \mathrm{C}$ with phosphate buffer solution ( $\mathrm{pH} 7.4$ ). Error bars represent standard deviation of the mean $(n=3)$.
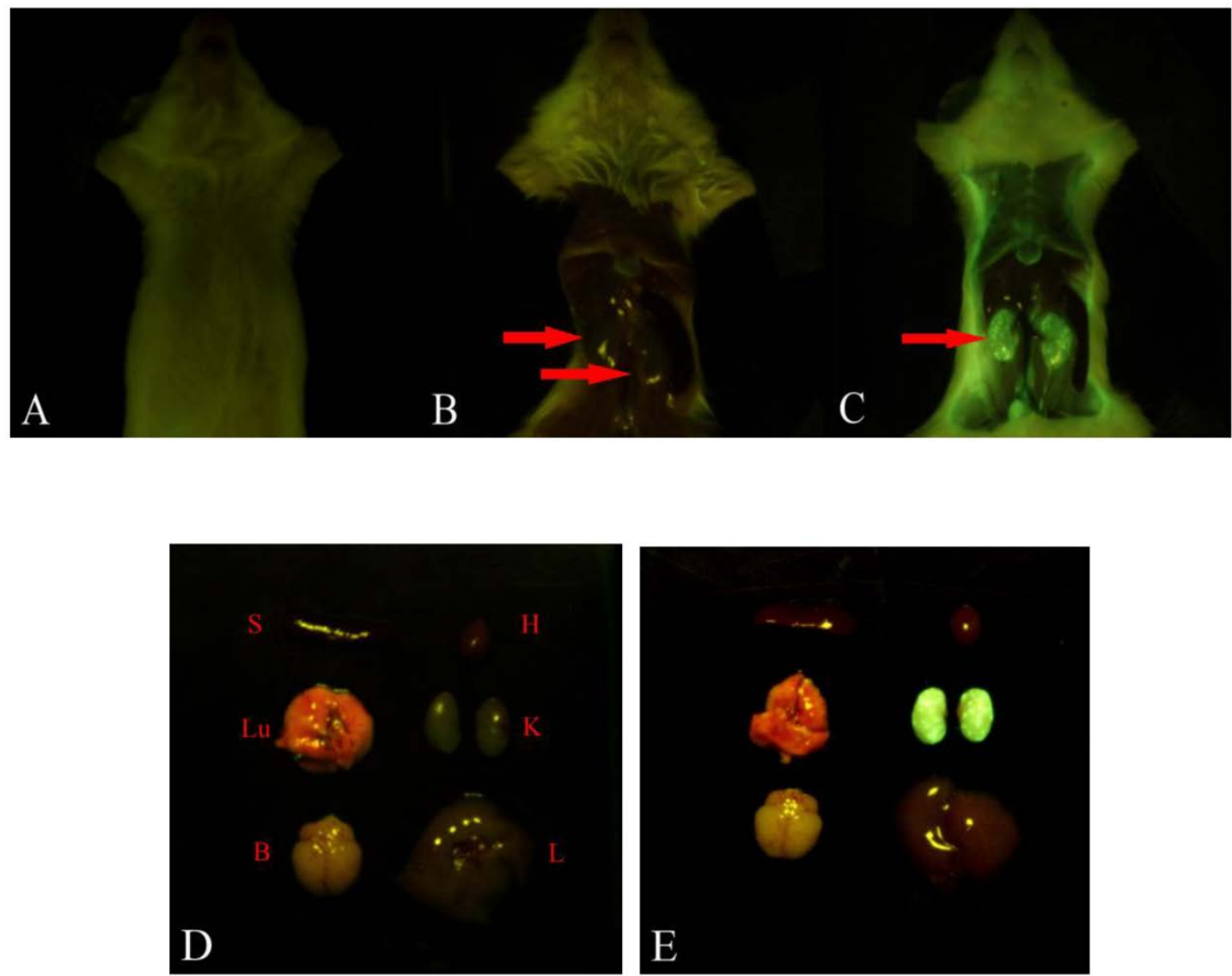

Figure 4. Fluorescence imaging of kidneys in mice after injection with LMWHC-Pre. The mouse was injected intravenously with FITC labeled LMWHC-Pre (100 mg kg-1) and the equivalent mixture of FITC and LMWHC-Pre respectively. All tissues were visualized by whole body imaging using a $470 \mathrm{~nm}$ light source. The mouse was prepared before exposing tissues $(\mathrm{A})$. Representative whole body distribution of FITC labeled LMWHC-Pre (C) and the mixture (B) $60 \mathrm{~min}$ after injection indicated renal specificity of LMWHC. Then, the tissues were collected and exposed to the same light source. The fluorescence images were recorded. Sectioned tissues of mice showed FITC labeled LMWHC-Pre (E) selectively accumulated in the kidneys. Conversely, no fluorescent signal was observed in any tissues in the mixture group (D). L, liver; K, kidney; H, heart; B: brain; S, spleen; Lu, lung.

\section{Preliminary study on pharmacodynamics of LMWHC-Pre}

The urinary protein content from each rat was analyzed and the results were listed in Table 2 . There was no significant difference at the beginning while after 7 days variability appeared among different groups. In the normal group (rats were housed without injection), only slight increase of urinary 
protein was found; in the blank group (rats were treated with a single dose of daunorubicin hydrochloride but without any other injections), urinary protein was notably increased; in the control (rats were treated with a single dose of daunorubicin hydrochloride and followed with injection of Prednisolone) and treatment group (rats were treated with a single dose of daunorubicin hydrochloride and followed with injection of LMWHC-Pre), urinary protein was also increased but still lower than the blank group $(p<0.05)$. Moreover, the treatment group was higher than that of the normal group $(p<0.05)$. After treatment for 14 days, urinary protein was further increased in the blank group but still increased slightly in the control and treatment group. Therefore, both LMWHC-Pre and prednisolone had the similar effect of decreasing urinary protein.

The plasma was analyzed by chemistry and the biochemical index analyzer and the results were shown in Table 3. After treatment for 14 days, the parameters in rats from control and treatment groups were improved when compared with that of blank group. Their biochemical indexes of ALB were higher than the blank group while BUN, CERA and Tc were lower than the blank group $(\mathrm{p}<0.05)$. Moreover, these indexes were similar to those of the normal group. These data suggested that LMWHC-Pre had significant impact in terms of plasma parameter comparing with rats treated with prednisolone, which meant it might cure the induced MCN and relieve the pathological symptom.

To evaluate the adverse effects of LMWHC-Pre after repeated administration in rats, prednisolone was employed as control. They were weighed every three days and their bone density after treatment of LMWHC-Pre and prednisolone was shown in Figure 5 and Table 4. The rats of prednisolone group were dysgenic compared with the other two groups with similar body weight. As a result, rats of the prednisolone group showed less body weights (approx 120 g) while those of the other two groups were more than $200 \mathrm{~g}$. Moreover, glucocorticoid-induced osteoporosis was hardly observed in the conjugate group whilst obvious osteoporosis was occurred in prednisolone group. From these data, we could conclude that LMWHC-Pre was not only efficient to the induced MCN, but it could also alleviate glucocorticoid-induced osteoporosis.

Table 2. Comparison of the content of urine protein of four groups $(n=5)$.

\begin{tabular}{llll}
\hline Group & \multicolumn{4}{l}{ The content of urine protein $(\mathrm{mg})$} & 14 days \\
\cline { 2 - 4 } & 0 days & 7 days & $10.73 \pm 4.29$ \\
\hline normal group & $7.64 \pm 2.56$ & $9.85 \pm 3.64$ & $130.76 \pm 40.31$ \\
blank group & $8.79 \pm 3.38$ & $47.47 \pm 15.67$ & $23.15 \pm 7.62$ \\
control group & $9.44 \pm 4.09$ & $17.86 \pm 6.01$ & $29.17 \pm 10.55$ \\
treatment group & $9.01 \pm 4.67$ & $23.16 \pm 7.34$ &
\end{tabular}

Normal group: the rats were housed without injection for 14 days.

Blank group: the rats were treated with a single dose of daunorubicin hydrochloride $\left(12 \mathrm{mg} \mathrm{kg}^{-1}\right)$ but without any other injections for 14 days.

Control group: the rats were treated with a single dose of daunorubicin hydrochloride $\left(12 \mathrm{mg} \mathrm{kg}^{-1}\right)$ and followed with injection of prednisolone $\left(3.0 \mathrm{mg} \mathrm{kg}^{-1} \cdot \mathrm{d}^{-1}\right)$ for 14 days.

Treatment group: the rats were treated with a single dose of daunorubicin hydrochloride (12 $\left.\mathrm{mg} \mathrm{kg}^{-1}\right)$ and followed with injection of LMWHC-Pre (39.1 $\mathrm{mg} \cdot \mathrm{kg}^{-1} \cdot \mathrm{d}^{-1}$, equal to the dose of prednisolone of the control group) for 14 days.

Table 3. Comparison of plasma biochemical indexes of each group after treatment for 14 days $(n=5)$.

\begin{tabular}{lllll}
\hline Groups & $\mathrm{ALB}\left(\mathrm{g} \cdot \mathrm{L}^{-1}\right)$ & $\mathrm{BUN}\left(\mathrm{mmol} \cdot \mathrm{L}^{-1}\right)$ & $\mathrm{CREA}\left(\mu \mathrm{mol} \cdot \mathrm{L}^{-1}\right)$ & $\mathrm{Tc}\left(\mathrm{mmol} \cdot \mathrm{L}^{-1}\right)$ \\
\hline normal group & $37.30 \pm 4.39$ & $7.53 \pm 1.41$ & $25.40 \pm 2.88$ & $0.83 \pm 0.18$ \\
blank group & $13.90 \pm 3.16$ & $17.43 \pm 6.03$ & $42.70 \pm 6.73$ & $3.98 \pm 1.46$ \\
control group & $34.60 \pm 4.74$ & $11.94 \pm 2.44$ & $21.20 \pm 6.73$ & $0.91 \pm 0.45$ \\
treatment group & $32.60 \pm 4.25$ & $10.58 \pm 3.40$ & $19.75 \pm 7.93$ & $1.30 \pm 0.16$ \\
\hline
\end{tabular}

Normal group: the rats were housed without injection for 14 days.

Blank group: the rats were treated with a single dose of daunorubicin hydrochloride $\left(12 \mathrm{mg} \mathrm{kg}^{-1}\right)$ but without any other injections for 14 days.

Control group: the rats were treated with a single dose of daunorubicin hydrochloride $\left(12 \mathrm{mg} \mathrm{kg}^{-1}\right)$ and followed with injection of prednisolone $\left(3.0 \mathrm{mg}^{\mathrm{kg}-1} \cdot \mathrm{d}^{-1}\right)$ for 14 days.

Treatment group: the rats were treated with a single dose of daunorubicin hydrochloride $\left(12 \mathrm{mg}^{\mathrm{kg}}-1\right)$ and followed with injection of LMWHC-Pre (39.1 $\mathrm{mg} \cdot \mathrm{kg}^{-1} \cdot \mathrm{d}^{-1}$, equal to the dose of prednisolone of the control group) for 14 days. 
Table 4. Comparison of rat bone mineral density in three groups $(n=3)$.

\begin{tabular}{ll}
\hline groups & Bone mineral density $\left(\mathrm{g} / \mathrm{cm}^{2}\right)$ \\
\hline normal group & $0.113 \pm 0.010$ \\
conjugate group & $0.103 \pm 0.005$ \\
prednisolone group & $0.084 \pm 0.003$ \\
\hline
\end{tabular}

Normal group: the rats were without injection and housed for 20 days.

Conjugate group: the rats were treated with LMWHC-Pre (39.1 $\mathrm{mg} \mathrm{kg}^{-1} \cdot \mathrm{d}^{-1}$, equal to the dose of prednisolone of the control group) for 20 days.

Prednisolone group: the rats were treated with prednisolone $\left(3.0 \mathrm{mg} \cdot \mathrm{kg}^{-1} \cdot \mathrm{d}^{-1}\right)$ for 20 days.

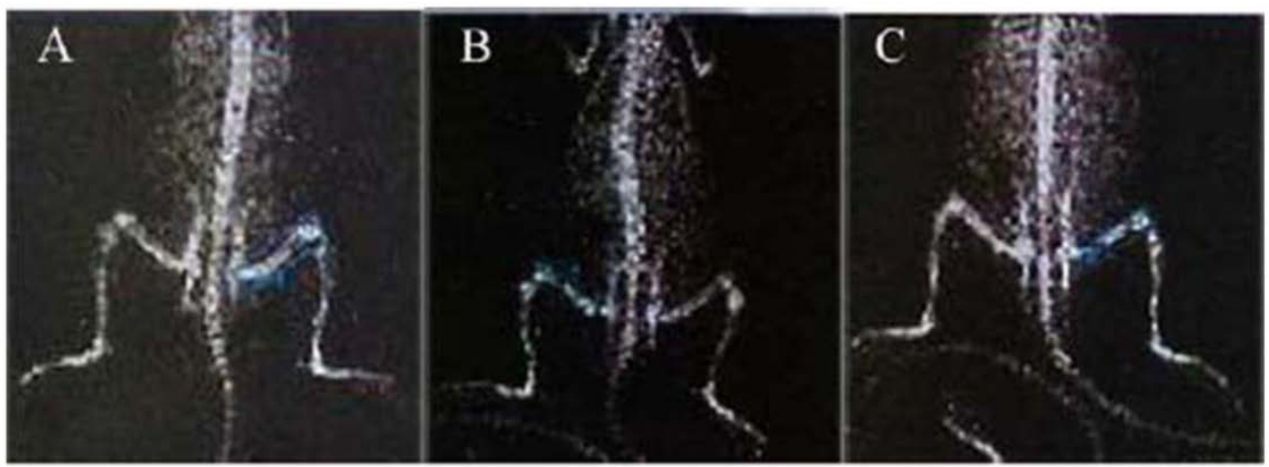

Figure 5. X-ray films of whole rat body. The rat in normal group (A) was without injection; the rat in prednisolone group (B) and conjugate group $(C)$ was injected intravenously with prednisolone $\left(3 \mathrm{mg} \mathrm{kg}^{-1}\right)$ and equivalent LMWHC-Pre respectively. The bone mineral density (BMD) of each rat was visualized by iDXA. After injection for 20 days, representative mean BMD of rat femur in prednisolone group $(B)$ was lower than that in normal group $(A)$ and conjugate group $(C)$, which revealed that LMWHC-Pre alleviated notably glucocorticoid-induced osteoporosis.

\section{Discussion}

In the previous studies, low molecular weight hydroxyethyl chitosan(LMWHC) has been demonstrated to be effective as a novel renal targeting carrier at both cellular and molecular levels [4, 14]. LMWHC can selectively accumulate in the kidneys, especially in the renal proximal tubules. Moreover, the uptake of LMWHC may be mediated by the megalin receptor [14]. In our study, preliminary pharmacodynamics study was performed in minimal change nephrosis (MCN) model to verify the targeting efficacy of LMWHC. The results revealed that LMWHC could specially accumulate in the kidneys and the LMWHC-Pre conjugate could decrease the level of urinary protein in $\mathrm{MCN}$ model rats significantly.

In the field of drug delivery system, optical imaging has been applied as a quick and powerful technique for the trace of drug and the carrier as well, thus enabling the evaluation of whether successful delivery to the desired organ or tissue structure is achieved $[18,19]$. In terms of chitosan, fluorescence labeling [20, 21] has been used to track both in vitro and in vivo behaviors of chitosan due to its easy conjugation with FITC and satisfactory stability [22, 23]. Optical imaging provides a valuable tool to follow the drug and the delivery vehicle on its journey through the body to ascertain whether successful delivery to the desired organ or tissue structure has taken place [19]. This strategy was also applied in our studies (Figure 4), which allowed visualization of the distribution of LMWHC-Pre in organs or tissues. From these fluorescent images, the LMWHC-Pre conjugate was found to be accumulated with high specificity in the kidney while there were negligible signals to come from other tissues, which verified targeting efficacy of the carrier reported before [4]. As is known to us, liver and spleen are the major organs to accumulate drug-polymer conjugate after i.v. injection. However, LMWHC-Pre was found to be mostly accumulated in the kidneys. Previous study [15] has reported that LMWHC can selectively distribute in renal proximal tubules whilst the chitosan was derivatized at the $\mathrm{N}$-position, such as $\mathrm{N}$-succinyl chitosan, is mainly taken up by liver [24-26]. The structure of chitosan has been found to be different from chitosan derivative [15]. Chitosan possess $-\mathrm{NH}_{2}$ in $\mathrm{C} 2$ position rather than -OH comparing with other polysaccharides such as dextran, pullulan, arabinogalactan. Therefore, it's concluded that amino groups in the structure probably play a key role on renal targeting profile of LMWHC-Pre. 
The clinical syndrome of MCN is characterized by numerous proteinuria, hypoalbuminemia, hyperlipidemia and obvious edema. Glucocorticoid, such as prednisolone, is a potent agent to treat $\mathrm{MCN}$ with possessing the effective rate of $90 \%$ [27] and the clinical symptoms may be alleviated within 7-28 days. However, glucocorticoid has severe adverse effect such as osteoporosis [2, 3, 28]. As potent osteopenic agents, glucocorticoids can produce negative calcium and bone balance via actions at many sites. The most significant adverse effect of glucocorticoid drugs on the skeleton is probably a direct inhibition of matrix synthesis by the osteoblasts, which causing the decrease of bone formation; reduction in calcium absorption from the intestine and the production of hypogonadism, particularly in men [29, 30]. Moreover, glucocorticoids induce defective osteoblast recruitment resulting in reduced bone formation, which deteriorates bone turnover [31]. In addition, glucocorticoids decrease bone mineral density (BMD) accompanied by defective osteoblastogenesis and osteoclastogenesis in the bone marrow and increased apoptosis of mature osteoblasts and osteocytes [32]. Osteoporosis occurs in at least $50 \%$ of persons who require long-term glucocorticoid therapy [30]. It is a common disorder characterized with an increase in bone resorption relative to bone formation, generally in conjunction with an increased rate of bone turnover [33]. Furthermore, the progressive decrease in bone mass leads to an increased susceptibility to osteoporosis-induced fracture, which results in substantial morbidity and mortality [34]. Therefore, osteoporosis is a considerable problem in health care due to its potentially severe consequences for both the patient and the health care system if a fracture occurs [35]. Measuring BMD has been considered as one method for early identification of individuals with the clinical therapy of osteoporosis, although it is only one of a number of risk factors for fracture [36-39]. Osteoporosis is diagnosed by the measurement of BMD, which is a highly heritable and multifactorial trait [40] and remains the single best predictor of primary osteoporotic disease [41]. Hence, the determination of BMD as an index was utilized to observe whether the LMWHC-Pre can alleviate the side effect resulted from prednisolone by dual-energy $\mathrm{x}$-ray absorptiometry. Indeed, the conjugate can decrease glucocorticoid-induced osteoporosis.

Daunorubicin (DRB) has been utilized to induce nephrotic syndrome model in previous work [17]. In contrast with adriamycin(ADR), there are more satisfactory repeatability and stability and lower mortality of rats [17] with DRB. In the pharmacodynamics study, urine protein of rats in the treatment group (rats were treated with a single dose of daunorubicin hydrochloride and followed with injection of LMWHC-Pre) is more than control group (rats were treated with a single dose of daunorubicin hydrochloride and followed with injection of Prednisolone) after treating with LMWHC-Pre, which is probably induced by meglin acceptor endocytosis in renal tubule. The procedure has inhibited the reabsorption of meglin acceptor to protein and polypeptide [14], which causes abnormal content of urine protein. In our studies, LMWHC-Pre has the similar efficiency with prednisolone and the partial reason is considered to be possibly attributed that LMWHC-Pre is targeting in the renal tubule rather than kidney glomerulus. Previous work has reported that the drug targeting renal tubule is also effective to disease in the renal glomerulus [42], but there is no related observation to be clarified in our experiments. However, these problems could be solved if further experiments are performed. Taken together, LMWHC-Pre has been shown to have therapeutic potential for targeting specially to the kidney and decreasing glucocorticoid-induced osteoporosis. Our future studies will devote greater efforts on further clinical pharmacodynamics of LMWHC-Pre, with the aim to clearly expound the possibility for renal targeting therapy.

\section{Conclusion}

In summary, low molecular weight hydroxyethyl chitosan-prednisolone (LMWHC-Pre) conjugate was synthesized, which could distribute specifically in the kidney and possess excellent targeting properties. LMWHC-Pre was found to be effective in reducing syndrome of $\mathrm{MCN}$ rats and with negligible glucocorticoid-induced osteoporosis could be observed, comparing with parent drug. The results obtained in this study demonstrated the excellent target efficiency, curative effect and reduced side effects of the LMWHC-Pre conjugate. Thus, LMWHC-Pre represents an extremely effective drug candidate for a specific treatment of renal diseases.

\section{Acknowledgements}

This study was supported by the National Natural Science Foundation of China (81202489).

\section{Competing Interests}

The authors have declared that no competing interest exists.

\section{References}

1. Haverdings RF, Hass M, Navis GJ, Van Loenen-Weemaes AM, Meijer DK, De Zeeuw D, et al. Renal targeting of captopril selectively enhances the intrarenal over the systemic effects of ACE inhibition in rats. Br J Pharmacol. 2002; 136(8):1107-16. 
2. Adachi JD. Glucocorticoid-induced osteoporosis. Osteoporos Int. 2009; 20(3):239-40.

3. Weinstein RS. Glucocorticoid-induced osteoporosis. Rev Endocr Metab Disord. 2001; 2(1):65-73.

4. Yuan ZX, Sun X, Gong T, Ding H, Fu Y, Zhang ZR. Randomly 50\% $\mathrm{N}$-acetylated low molecular weight chitosan as a novel renal targeting carrier. J Drug Target. 2007; 15(4):269-78.

5. Wilk S, Mizoguchi H, Orlowski M. ү-Glutamyl dopa: A kidney-specific dopamine precursor. J Pharmacol Exp Ther. 1978; 206(1):227-32.

6. Haas M, De Zeeuw D, Van Zanten A, Meijer DK. Quatification of renal low-molecular-weight protein handling in the intact rat. Kidney Int. 1993; 43(4):949-54.

7. Kok RJ, Grijpstra F, Walthuis RB, Moolenaar F, De Zeeuw D, Meijer DK. Specific delivery of captopril to the kidney with the prodrug captopril-lysozyme. J Pharmacol Exp Ther. 1999; 288(1):281-5.

8. Haverdings RF, Haas M, Greupink AR, De Vries PA, Moolenaar F, De Zeeuw D, et al. Potential and limitations of the low molecular-weight protein lysozyme as a carrier for renal drug targeting. Ren Fail. 2001; 23(3-4):397-409.

9. Suzuki K, Susaki H, Okuno S, Sugiyama Y. Renal drug targeting using a vector "alkylgycoside". J Pharmacol Exp Ther. 1999; 288(1):57-64.

10. Suzuki K, Susaki H, Okuno S, Yamada H, Watanabe HK, Sugiyama Y. Specific renal delivery of sugar modified low-molecular-weight peptides. J Pharmacol Exp Ther. 1999; 288(2):888-97.

11. Kamada H, Tsutsumi Y, Sato-Kamada K, Yamamoto Y, Yoshioka Y, Okamoto T, et al. Synthesis of a poly (vinylpyrrolidone-co-dimethyl maleic antydride) co-polymer and its application as renal targeting carrier. Nat Biotechnol. 2003; 21(4):399-404.

12. Kodaira H, Tsutsumi Y, Yoshioka Y, Kamada H, Kaneda Y, Yamamoto $\mathrm{Y}$, et al. The targeting of anionized polyvinylpyrrolidone to the renal system. Biomaterials. 2004; 25(18):4309-15.

13. Yamamoto Y, Tsutsumi Y, Yoshioka Y, Kamada H, Sato-Kamada K, Okamoto T, et al. Poly (vinylprrolidone-co-dimethylmaleic acid) as a novel renal targeting carrier. J Control Release. 2004; 95(2):229-37.

14. Yuan ZX, Zhang ZR, Zhu D, Sun X, Gong T, Liu J, Luan CT. Specific renal uptake of randomly $50 \% \mathrm{~N}$-acetylated low molecular weight chitosan. Mol Pharm. 2009; 6(1):305-14.

15. Yuan ZX, Li JJ, Zhu D, Sun X, Gong T, Zhang ZR. Enhanced accumulation of low molecular weight chitosan in kidneys: a study on the influence of N-acetylation of chitosan on the renal targeting. J Drug Target. 2011; 19(7):540-51.

16. Mcleod AD, Friend DR, Tozer TN. Glucocorticoid-dextran conjugates as potential prodrugs for colon-specific delivery: Hydrolysis in rat gastrointestinal tract contents. J Pharm Sci. 1994; 83(9):1284-8.

17. Sternberg SS, Philips FS. Biphasic intoxication and nephritic syndrome in rats given daunomycin. Proc Am Assoc Cancer Res, 1967; 8:64-70.

18. Hyung Park J, Kwon S, Lee M, Chung H, Kim JH, Kim YS, et al. Self-assembled nanoparticles based on glycol chitosan bearing hydrophobic moieties as carriers for doxorubicin: In vivo biodistribution and anti-tumor activity. Biomaterials. 2006; 27(1):119-26.

19. Licha $\mathrm{K}$, Olbrich $\mathrm{C}$. Optical imaging in drug discovery and diagnostic applications. Adv Drug Deliv Rev. 2005; 57(8):1087-108.

20. Onishi H, Machida Y. Biodegradation and distribution of water-soluble chitosan in mice. Biomaterials. 1999; 20(2):175-82.

21. Pinaud F, Michalet X, Bentolila LA, Tsay JM, Doose S, Li JJ, et al. Advances in fluorescence imaging with quantum dot bio-probes. Biomaterials. 2006; 27(9):1679-87.

22. Huang M, Ma Z, Khor E, Lim LY. Uptake of FITC-chitosan nanoparticles by A549 cells. Pharma Res. 2002; 19(10):1488-94.

23. Porporatto C, Bianco ID, Correa SG. Local and systemic activity of the polysaccharide chitosan at lymphoid tissues after oral administration. J Leukoc Biol. 2005; 78(1):62-9.

24. Kamiyama K, Onishi H, Machida Y. Biodisposition characteristics of $\mathrm{N}$-succinyl-chitosan and glycol-chitosan in normal and tumor bearing mice. Biol Pharm Bull. 1999; 22(2):179-86.

25. Kato Y, Onishi H, Machida Y. Biological characteristics of lactosaminated $\mathrm{N}$-succinyl-chitosan as a liver-specific drug carrier in mice. J Control Release. 2001; 70(3):295-307.

26. Kato $\mathrm{Y}$, Onishi $\mathrm{H}$, Machida $\mathrm{Y}$. N-succinyl-chitosan as a drug carrier: water-insoluble and water-soluble conjugates. Biomaterials. 2004; 25(5):907-15.

27. Xie Y, Tan Y, L YB. Development and advance of minimal change nephropathy model in rats. Chin J Lab Anim Sci. 2001; 11(3):184-87.

28. Nishioka T, Kurayama H, Yasuda T, Udagawa J, Matsumura C, Niimi H Nasal administration of salmon calcitonin for prevention of glucocorticoid-induced osteoporosis in children with nephrosis. J Pediatr. 1991; 118(5):703-7.
29. Reid IR. Glucocorticoid osteoporosis-mechanisms and management. Eur J Endocrinol. 1997; 137(3):209-17.

30. Lukert BP, Raisz LG. Glucocorticoid-Induced Osteoporosis: Pathogenesis and Management. Ann Intern Med. 1990; 112(5):352-64.

31. Parfitt AM, Villanueva AR, Foldes J, Rao DS. Relations between histologic induces of bone formation: Implications for the pathogenesis of spinal osteoporosis. J Bone Miner Res. 1995; 10(3):466-73.

32. Weinstein RS, Jilka RL, Parffit AM, Manolagas SC. Inhibition of osteoblastogenesis and promotion of apoptosis of osteoblasts and osteocytes by glucocorticoids. Potential mechanisms of their deleterious effects on bone. J Clin Invest. 1998; 102(2):274-82.

33. Riggs BL, Melton LJ. The prevention and treatment of osteoporosis. N Engl J Med. 1992; 327(9):620-7.

34. Peck WA, Burckhardt P, Christiansen C, Fleisch HA. Consensus development conference: diagnosis; prophylaxis, and treatment of osteoporosis. Am J Med. 1993; 94(6):646-50.

35. Marshall D, Johnell O, Wedel H. Meta-analysis of how well measures of bone mineral density predict occurrence of osteoporotic fractures. BMJ. 1996; 312(7041):1254-9.

36. Melton LJ, Eddy DM, Johnston CC. Screening for osteoporosis. Ann Intern Med. 1990; 112(7):516-28.

37. Law MR, Wald NJ, Meade TW. Strategies for prevention of osteoporosis and hip fracture. BMJ. 1991; 303(6800):453-9.

38. Grisso JA, Kelsey JL, Strom BL, Chiu GY, Maislin G, O'Brien LA, et al. Risk factors for falls as a cause of hip fracture in women. N Engl J Med. 1991; 324(19):1326-31.

39. Cummings SR, Nevitt MC, Browner WS, Stone K, Fox KM, Ensrud KE, et al. Risk factors for hip fracture in white women. N Engl J Med. 1995; 332(12):767-73.

40. Richards JB, Rivadeneira F, Inouye M, Pastinen TM, Soranzo N, Wilson SG, et al. Bone mineral density, osteoporosis, and osteoporotic fractures: a genome-wide association study. Lancet. 2008; 371(9623):1505-12.

41. Kanis JA, Borgstrom F, De Laet C, Johansson H, Johnell O, Jonsson B, et al. Assessment of fracture risk. Osteoporos Int. 2005; 16(6):581-9.

42. Haas M, Moolenaar F, Meijer DK, De Zeeuw D. Specific drug delivery to the kidney. Cardiovasc Drugs Ther. 2002; 16(6):489-96. 